\title{
ALTERAÇÕES EM ALGUNS ATRIBUTOS QUÍMICOS DO SOLO DECORRENTES DA IRRIGAÇÃO E ADUBAÇÃO NITROGENADA E POTÁSSICA EM BANANEIRA APÓS DOIS CICLOS DE CULTIVO ${ }^{1}$
}

\author{
LUIZ ANTONIO JUNQUEIRA TEIXEIRA², WILLIAM NATALE, CARLOS RUGGIERO ${ }^{4}$
}

\begin{abstract}
RESUMO - Com o objetivo de avaliar alterações em atributos químicos do solo causadas pela adubação nitrogenada e potássica em bananeira sob duas condições de irrigação, coletaram-se amostras de um Latossolo Vermelho Eutroférrico típico (Eutrustox), provenientes de um experimento de campo executado em Jaboticabal (SP) durante dois anos. Empregou-se o delineamento experimental de blocos ao acaso com os tratamentos em parcelas subdivididas, sendo as parcelas principais constituídas por dois regimes hídricos: irrigado (microaspersão) e sequeiro, e as subparcelas, pelas combinações de quatro doses de nitrogênio $\left(0 ; 200 ; 400\right.$ e $800 \mathrm{~kg} \mathrm{ha}^{-1}$ ano $^{-1}$ de N) e quatro de potássio $\left(0 ; 300 ; 600 \mathrm{e} 900 \mathrm{~kg} \mathrm{ha}^{-1}\right.$ ano $\left.^{-1} \mathrm{de} \mathrm{K}_{2} \mathrm{O}\right)$. A adubação nitrogenada causou decréscimos significativos nos valores de pH do solo, saturação por bases e teor de $\mathrm{Mg}$ trocável. O cultivo de bananeiras, especialmente sob irrigação, determinou redução significativa nos teores de $\mathrm{K}$ trocável do solo em dois ciclos de produção. Os efeitos da cultura sobre alguns atributos do solo indicam a necessidade de monitoramento periódico da fertilidade, visando à manutenção de condições satisfatórias para produção, especialmente quanto à acidez e aos teores de $\mathrm{K}$ e Mg trocáveis.
\end{abstract}

Termos para indexação: análise de solo, banana, nitrogênio, potássio, Musa spp.

\section{CHANGES ON SOME SOIL CHEMICAL PROPERTIES DUE TO NITROGEN AND POTASSIUM FERTILIZATION AND IRRIGATION IN BANANA PLANTATION AFTER TWO CROP CYCLES}

\begin{abstract}
Soil samples were analyzed with the objective of investigating changes on some soil chemical properties due to nitrogen and potassium fertilization and irrigation in a banana plantation. The samples were collected in a field experiment carried out on an Eutrustox (Latossolo Vermelho Eutroférrico típico) in São Paulo State, Brazil, during two crop seasons. A split-plot design was used with irrigation (micro-sprinkler) and no irrigation applied to main plots and a combination of four rates of $\mathrm{N}(0,200,400$ and $800 \mathrm{~kg} \mathrm{~N} \mathrm{ha}^{-1}$ year $\left.^{-1}\right)$ and $\mathrm{K}\left(0,300,600\right.$ and $900 \mathrm{~kg} \mathrm{~K}_{2} \mathrm{O} \mathrm{ha}^{-1}$ year $\left.^{-1}\right)$ as the sub-plots treatments. Soil $\mathrm{pH}$, base saturation and exchangeable $\mathrm{Mg}$ decreased with increasing in $\mathrm{N}$ rates. Exchangeable $\mathrm{K}$ was significantly reduced after two crop cycles with a greater $\mathrm{K}$ depletion in irrigated than in non-irrigated plots. The effects of cropping on soil properties strengthened the importance of checking fertility (especially acidity, exchangeable $\mathrm{Mg}$ and $\mathrm{K}$ ) periodically in order to keep the sustainability of banana plantations.
\end{abstract}

Index terms: Musa spp., soil analysis

\section{INTRODUÇÃO}

A bananeira é uma planta de crescimento rápido que necessita, para seu desenvolvimento e produção normais, de uma concentração elevada de nutrientes disponíveis no solo. Esses podem ser fornecidos, em parte, pelo solo e pela reciclagem no sistema solo-planta; entretanto, para obtenção de produções economicamente rentáveis, é imprescindível a aplicação de fertilizantes em quantidades e proporções adequadas ao extraído pela cultura (Soto, 1992). Segundo Lahav \& Turner (1983), os nutrientes minerais necessários à bananeira podem ser apenas parcialmente supridos a partir das reservas do solo. Como exemplo, citaram que aproximadamente $1500 \mathrm{~kg} \mathrm{ha}^{-1}$ ano $^{-1}$ de K devem ser absorvidos pelas plantas para um rendimento de frutos de $50 \mathrm{t} \mathrm{ha}^{-1}$ ano $^{-1}$. Em cultivos de alto rendimento $\left(70 \mathrm{tha}^{-1}\right.$ ano $^{-}$
1) e para as condições da América Central, López \& Espinosa (1995) estimaram uma quantidade de nutrientes exportada com os frutos superior a $400 \mathrm{~kg} \mathrm{ha}^{-1}$ ano $^{-1}$ de K, 125 de N e 15 de P. Esses autores destacaram que a manutenção de rendimentos elevados ao longo do tempo depende da reposição dos nutrientes exportados por meio de adubações.

Além da exportação, podem ocorrer perdas de nutrientes do sistema solo-planta devido à volatilização, erosão e lixiviação. Perdas de nutrientes por lixiviação e escorrimento superficial em bananais, sob diversas condições de solo e clima, foram avaliadas numa série de trabalhos descritos por Godefroy et al. (1975), nos quais se determinaram perdas entre 60 e $85 \%$ dos fertilizantes aplicados (exceto para $\mathrm{P}$ ), sendo $\mathrm{N}, \mathrm{K}, \mathrm{Ca}$ e $\mathrm{Mg}$ perdidos predominantemente ( 85 a 95\%) por lixiviação. Em estudo realizado num solo caulinítico, com $530 \mathrm{~g} \mathrm{~kg}^{-1}$ de argila, observaram-se

1 (Trabalho 031/2001). Recebido: 06/02/2001. Aceito para publicação: 28/08/2001. Parte da Tese de Doutorado do primeiro autor apresentada à FCAV/UNESP, Jaboticabal, SP. Apoio financeiro: FAPESP (96/4209-4).

2 Pesquisador do Centro de Fruticultura/IAC. Cx. Postal 28. 13001-970, Campinas, SP. teixeira@iac.br.

3 Professor Adjunto, Departamento de Solos e Adubos, FCAV/Unesp - Campus de Jaboticabal. 14870-000, Jaboticabal - SP. E-mail: natale@fcav.unrf.br

- Bolsista do CNPq.

4 Professor Titular, Departamento de Produção Vegetal, FCAV/Unesp. 
também perdas elevadas de $\mathrm{N}$ e $\mathrm{K}$ pela água de drenagem no perfil do solo (Godefroy \& Dormoy, 1990).

Num experimento visando a estudar a resposta de bananeiras à aplicação de calcário, no Vale do Ribeira (SP), Saes (1995) monitorou a evolução da fertilidade do solo e teve que reaplicar os tratamentos de calcário após três ciclos de cultivo, devido a grandes alterações no $\mathrm{pH}$ e na saturação por bases. Bataglia \& Santos (1999) detectaram incrementos lineares na acidez do solo cultivado com seringueira em função de doses de N. Em citros, alterações significativas no $\mathrm{pH}$ do solo e saturação por bases foram atribuídas à adubação nitrogenada por Sanches et al. (1999).

O objetivo deste trabalho foi estudar alterações em atributos químicos de um solo sob cultivo de bananeira em função da adubação nitrogenada e potássica e da irrigação durante dois ciclos de produção.

\section{MATERIAL E MÉTODOS}

O experimento foi realizado em Jaboticabal-SP (altitude: $575 \mathrm{~m}$; latitude: $21^{\circ} 15^{\prime} \mathrm{S}$ ), com clima mesotérmico de inverno seco (Cwa - Classificação de Köeppen) e solo classificado como Latossolo Vermelho Eutroférrico típico. Valores médios de alguns atributos do solo, em amostragem realizada na época da instalação do experimento, encontram-se na Tabela 1.

Empregou-se o delineamento experimental casualizado em blocos completos, com os tratamentos arranjados em parcelas subdivididas, sendo as parcelas principais constituídas por dois regimes hídricos: irrigado (microaspersão) e sequeiro, e as subparcelas, pelas combinações de quatro doses de nitrogênio $\left(0 ; 200 ; 400\right.$ e $800 \mathrm{~kg} \mathrm{ha}^{-1}$ ano ${ }^{-1}$ de $\left.\mathrm{N}\right)$ e quatro de potássio $(0 ; 300$; 600 e $900 \mathrm{~kg} \mathrm{ha}^{-1} \mathrm{ano}^{-1}$ de $\mathrm{K}_{2} \mathrm{O}$ ). As doses de adubo (nitrato de amônio e cloreto de potássio, como fontes de $\mathrm{N}$ e $\mathrm{K}$, respectivamente) foram aplicadas na superfície do solo, sem incorporação, parceladas em quatro vezes durante a estação das chuvas.

Antes da instalação do experimento, a área vinha sendo utilizada com cultivos anuais de verão (soja e milho), em plantio convencional. No final de 1996, foram aplicadas $2,5 \mathrm{t} \mathrm{ha}^{-1}$ de calcário dolomítico. $\mathrm{O}$ manejo inicial do solo constou de uma operação de subsolagem e aplicação de termofosfato (16 \% de $\mathrm{P}_{2} \mathrm{O}_{5}$ solúveis em ácido cítrico a $2 \%$ ), em área total, na dose de $90 \mathrm{~kg} \mathrm{ha}^{-1}$ de $\mathrm{P}_{2} \mathrm{O}_{5}$, incorporado com grade pesada. Fez-se a adubação de plantio com $15 \mathrm{~L} /$ cova de esterco de curral e $80 \mathrm{~kg} \mathrm{ha}^{-1} \mathrm{de}_{2} \mathrm{O}_{5}$ (termofosfato) aplicados nas covas. O bananal foi implantado empregando-se mudas micropropagadas in vitro da cultivar Nanicão (Musa AAA subgrupo Cavendish), em outubro de 1997, num espaçamento de 2 por 2,6 $\mathrm{m}$.

A irrigação (microaspersão) foi manejada a partir de dados meteorológicos (evaporação medida no tanque Classe A e precipitação), com intervalo entre regas de dois ou três dias, visando a atender às exigências hídricas da cultura, de acordo com as recomendações de Doorenbos \& Kassam (1979).

Os efeitos dos tratamentos sobre alguns atributos do solo foram avaliados por meio de amostragens anuais (set/97, set/98 e set/99) realizadas em cada subparcela, antes da aplicação dos adubos, com 12 pontos por amostra composta. Fizeram-se as duas primeiras amostragens nas camadas de 0 a $20 \mathrm{~cm}$ e de 20 a $40 \mathrm{~cm}$; a terceira amostragem estendeu-se até a camada de 40 a $60 \mathrm{~cm}$. Todas as amostragens foram realizadas na área de aplicação dos fertilizantes, a qual variou com o caminhamento do bananal. As análises de solo seguiram os métodos descritos por Raij \& Quaggio (1983).

Por meio da amostragem inicial, caracterizaram-se as unidades experimentais de modo individualizado, permitindo, com o decorrer do trabalho, que se estimasse a evolução da fertilidade em função dos tratamentos de irrigação e adubação. Calcularamse as variações (D) de $\mathrm{pH}$, saturação por bases, $\mathrm{K} \mathrm{e} \mathrm{Mg}$ trocáveis, após um e dois anos, em relação à amostragem inicial. Como as amostragens foram realizadas em áreas de solo diferentes ao final do primeiro e segundo anos, devido ao "caminhamento" das touceiras, optou-se por cotejar esses resultados com aqueles obtidos na amostragem inicial, não fazendo comparações entre épocas.

Os efeitos dos tratamentos aplicados às parcelas principais (sequeiro e irrigação) foram avaliados empregando-se o teste F. Para as situações nas quais se detectaram efeitos significativos dos tratamentos de adubação, foram ajustadas equações de regressão relacionando doses de potássio e nitrogênio com as variáveis resposta, para condições de sequeiro e irrigação. Fez-se, também, a comparação dos parâmetros dos modelos para cada regime hídrico, visando a determinar se os efeitos das variáveis independentes diferiam em função da irrigação. Nas análises de variância, empregou-se o módulo GLM (General Linear Models) do SAS, segundo Freund \& Litttell (1981); os parâmetros dos modelos de regressão foram estimados por máxima verossimilhança, empregando-se o módulo MIXED (Mixed Models), conforme Littell et al. (1996).

\section{RESULTADOS E DISCUSSÃO}

Na Tabela 2, destacam-se os efeitos da adubação nitrogenada sobre as alterações de $\mathrm{pH}$ e saturação por bases e da adubação potássica sobre o teor de K trocável, nas duas profundidades de amostragem e nos dois períodos de cultivo.

A aplicação de $\mathrm{N}$ causou significativo decréscimo no pH do solo e na saturação por bases, observando-se uma redução de $\mathrm{pH}$ superior a uma unidade ao final de um ano (Figura 1-A). A acidificação foi proporcional à dose de $\mathrm{N}$ aplicada, numa relação quadrática. A saturação por bases (V) também foi afetada pela adubação nitrogenada (Figura 1-B). Na amostragem inicial, V era de aproximadamente $60 \%$, após dois anos, com uma dose de $700 \mathrm{~kg} \mathrm{ha}^{-1}$ ano $^{-1}$ de N, na forma de nitrato de amônio, e estimouse uma redução para $39 \%$. A capacidade de acidificar o solo de alguns fertilizantes nitrogenados é bastante conhecida e deriva de reações que produzem $\mathrm{H}^{+}$(nitrificação) e da perda de cátions para camadas mais profundas, acompanhando o ânion $\mathrm{NO}_{3} \cdot$ (Tisdale et al., 1985). Em bananeira, Saes (1995) observou decréscimo significativo de $\mathrm{pH}$ e saturação por bases após três anos de cultivo.

Para bananeiras, a acidificação causada pela adição de $\mathrm{N}$ representa um risco à manutenção de produtividades elevadas no decorrer do tempo, pois recomenda-se, manter a saturação por bases, acima de $60 \%$ (Teixeira et al., 1996). Além disso, sabese que as bananeiras exigem suprimento adequado de $\mathrm{Mg}$, especialmente em áreas adubadas com potássio (Moreira \& 
Hiroce, 1978; Lichtemberg \& Malburg, 1983; Delvaux, 1995). Nesse experimento, além de uma expressiva redução na saturação por bases em decorrência da adubação nitrogenada (Figura 1-B), o teor de Mg trocável também foi afetado (Figura 2), atingindo níveis inferiores ao mínimo recomendado para a cultura $\left(9 \mathrm{mmol}_{\mathrm{c}} \mathrm{dm}^{-3}\right)$. Estimou-se que aplicações de nitrogênio, em doses superiores a $336 \mathrm{~kg} \mathrm{ha}^{-1} \mathrm{ano}^{-1}$ de $\mathrm{N}$, determinaram que o teor de $\mathrm{Mg}$ trocável do solo ficasse abaixo de $9 \mathrm{mmol}_{\mathrm{c}} \mathrm{dm}^{-3}$ após o segundo ciclo de cultivo. Esses aspectos acentuam a importância do monitoramento periódico da fertilidade do solo e do estado nutricional das plantas.

As alterações médias de alguns atributos de solo decorrentes da irrigação são apresentadas na Tabela 3. Ao final do primeiro ano, os incrementos de $\mathrm{K}$ trocável nas camadas de 0 a $20 \mathrm{~cm}$ e 20 a $40 \mathrm{~cm}$ foram menores na área irrigada. Depois de dois anos, a irrigação determinou, na média de todos os tratamentos de $\mathrm{N}$ e $\mathrm{K}$, diminuição no teor de $\mathrm{K}$ trocável do solo para as duas camadas, em relação à amostragem inicial. O fato de se obterem $\Delta \mathrm{K}$ menores sob irrigação, indica que se deva ter um cuidado especial na estimativa dos nutrientes a serem repostos via adubação em áreas irrigadas.

Pode-se creditar os menores $\Delta \mathrm{K}$ (diminuição no teor de $\mathrm{K}$ trocável) encontrados na área irrigada, parcialmente, à maior acumulação de K pelas plantas sob irrigação. Em dois ciclos de produção, estimou-se que as plantas acumularam, na parte aérea, $741 \mathrm{~kg} \mathrm{ha}^{-1}$ de $\mathrm{K}$ em sequeiro e $1078 \mathrm{~kg} \mathrm{ha}^{-1}$ de K sob irrigação. Possíveis incrementos nas perdas por lixiviação não foram confirmados, pois não houve aumento na movimentação de $\mathrm{K}$ para camadas mais profundas (até $60 \mathrm{~cm}$ ) associado à irrigação. Na figura 3-C, observa-se que os teores de K trocável na camada de 40 a 60 cm não aumentaram em função da irrigação após dois ciclos de cultivo.

Na Figura 3, constata-se, também, que o potássio aumentou em todo o perfil do solo $(0 \mathrm{a} 60 \mathrm{~cm})$ proporcionalmente

TABELA 1 - Análise química do solo da área experimental. Valores médios para toda área de amostras coletadas na implantação do bananal (setembro de 1997).

\begin{tabular}{|c|c|c|c|c|c|c|c|c|c|c|}
\hline Profundidade & $\mathrm{pH}\left(\mathrm{CaCl}_{2}\right)$ & $\mathrm{MO}$ & $\mathrm{P}_{\text {(resina) }}$ & $\mathrm{K}$ & $\mathrm{Ca}$ & $\mathrm{Mg}$ & $\mathrm{H}+\mathrm{Al}$ & SB & $\mathrm{T}$ & $\mathrm{V}$ \\
\hline ----- cm ----- & & $\mathrm{g} \mathrm{dm}^{-3}$ & $\mathrm{mg} \mathrm{dm}^{-3}$ & ----- & ---- & $-\mathrm{mm}$ & $\mathrm{c} \mathrm{dm}^{-3}-$ & -1- & ----- & $\%$ \\
\hline $0-20$ & 5,3 & 22 & 46 & 3,4 & 32 & 13 & 34 & 48,4 & 82,4 & 59 \\
\hline $20-40$ & 5,2 & 18 & 20 & 2,9 & 25 & 10 & 32 & 37,9 & 69,9 & 54 \\
\hline
\end{tabular}

TABELA 2 - Resumo da análise de variância das alterações de $\mathrm{pH}$ do solo $(\Delta \mathrm{pH})$, percentagem de saturação por bases $(\Delta \mathrm{V})$, teores de potássio $(\Delta \mathrm{K})$ e magnésio $(\Delta \mathrm{Mg})$ trocáveis nos dois primeiros anos de cultivo de bananeiras, em duas profundidades

\begin{tabular}{|c|c|c|c|c|c|c|c|c|c|}
\hline Causa da & & & $\Delta^{(1)} \mathrm{pH}$ & & $\Delta \mathrm{V}$ & & $\Delta \mathrm{K}$ & & $\Delta \mathrm{Mg}$ \\
\hline Variação & $\mathrm{GL}^{-}$ & Prof $1^{(2)}$ & Prof $2^{(3)}$ & Prof 1 & Prof 2 & Prof 1 & Prof 2 & Prof 1 & Prof 2 \\
\hline
\end{tabular}

Após um ano de cultivo

\begin{tabular}{lrrrrrrrrr} 
Irrigação (I) & 1 & 0,5668 & $\mathbf{0 , 0 0 8 0}$ & 0,2039 & 0,1940 & 0,1020 & $\mathbf{0 , 0 4 8 3}$ & 0,0868 & $\mathbf{0 , 0 4 3 3}$ \\
Nitrogênio (N) & 3 & $<\mathbf{0 , 0 0 0 1}$ & $<\mathbf{0 , 0 0 0 1}$ & $<\mathbf{0 , 0 0 0 1}$ & $<\mathbf{0 , 0 0 0 1}$ & $\mathbf{0 , 0 0 1 3}$ & 0,9891 & $\mathbf{0 , 0 0 0 4}$ & $<\mathbf{0 , 0 0 0 1}$ \\
Potássio (K) & 3 & 0,0983 & $\mathbf{0 , 0 4 2 3}$ & 0,6716 & 0,4236 & $<\mathbf{0 , 0 0 0 1}$ & $<\mathbf{0 , 0 0 0 1}$ & $\mathbf{0 , 0 3 2 1}$ & 0,1558 \\
N x K & 9 & 0,0606 & 0,0919 & 0,0645 & $\mathbf{0 , 0 2 2 3}$ & $\mathbf{0 , 0 3 7 6}$ & 0,9902 & 0,0925 & 0,0890 \\
I x N & 3 & 0,4511 & 0,8842 & 0,0517 & 0,0901 & 0,7394 & 0,4700 & 0,4478 & 0,1242 \\
I x K & 3 & 0,6741 & 0,1480 & 0,0702 & 0,0601 & $\mathbf{0 , 0 0 0 3}$ & 0,7957 & 0,2903 & 0,2677 \\
I x N x K & 9 & 0,9224 & 0,9687 & 0,9709 & 0,5958 & 0,9318 & 0,4216 & 0,4373 & 0,2578 \\
& & & & & Após dois anos de cultivo & & & \\
Irrigação (I) & 1 & 0,2177 & 0,6257 & $\mathbf{0 , 0 2 4 8}$ & 0,3956 & $\mathbf{0 , 0 4 0 7}$ & $\mathbf{0 , 0 1 5 6}$ & 0,7463 & $\mathbf{0 , 0 4 3 8}$ \\
Nitrogênio (N) & 3 & $<\mathbf{0 , 0 0 0 1}$ & $<\mathbf{0 , 0 0 0 1}$ & $<\mathbf{0 , 0 0 0 1}$ & $\mathbf{0 , 0 0 0 5}$ & 0,5978 & 0,6548 & 0,1933 & $\mathbf{0 , 0 2 8 4}$ \\
Potássio (K) & 3 & 0,6567 & 0,6632 & 0,4266 & 0,5044 & $<\mathbf{0 , 0 0 0 1}$ & $<\mathbf{0 , 0 0 0 1}$ & 0,3416 & $\mathbf{0 , 0 3 6 0}$ \\
N x K & 9 & 0,7157 & 0,6260 & 0,6224 & 0,5341 & 0,1199 & 0,8819 & 0,8774 & 0,4421 \\
I x N & 3 & 0,7610 & $\mathbf{0 , 0 0 7 7}$ & 0,3505 & $\mathbf{0 , 0 3 9 6}$ & 0,1442 & 0,8831 & 0,4282 & $\mathbf{0 , 0 1 0 1}$ \\
I x K & 3 & 0,2670 & 0,5064 & 0,3080 & 0,1085 & $<\mathbf{0 , 0 0 0 1}$ & 0,0967 & 0,3869 & 0,1906 \\
I x N x K & 9 & 0,8545 & 0,7801 & 0,6360 & 0,7932 & 0,3187 & 0,9486 & 0,7259 & 0,2606 \\
\hline
\end{tabular}

Valores em negrito: $p<0,05$ (F significativo a $5 \%$ de probabilidade); ${ }^{(1)} \mathrm{D}=$ valor obtido nas amostragens após um ou dois anos de cultivo - valor na amostragem inicial; (2) Prof $1=0$ a $20 \mathrm{~cm}$; ${ }^{(3)}$ Prof $2=20$ a $40 \mathrm{~cm}$; (4) Valor $p=$ probabilidade de erro tipo I associada ao teste $\mathrm{F}$. 
TABELA 3 - Médias das alterações de $\mathrm{pH}$ do solo $(\Delta \mathrm{pH})$, percentagem de saturação por bases $(\Delta \mathrm{V})$ e teores de potássio $(\Delta \mathrm{K})$ e magnésio $(\Delta \mathrm{Mg})$ trocáveis nos dois primeiros anos de cultivo de bananeiras e em duas profundidades de amostragem sob dois regimes hídricos

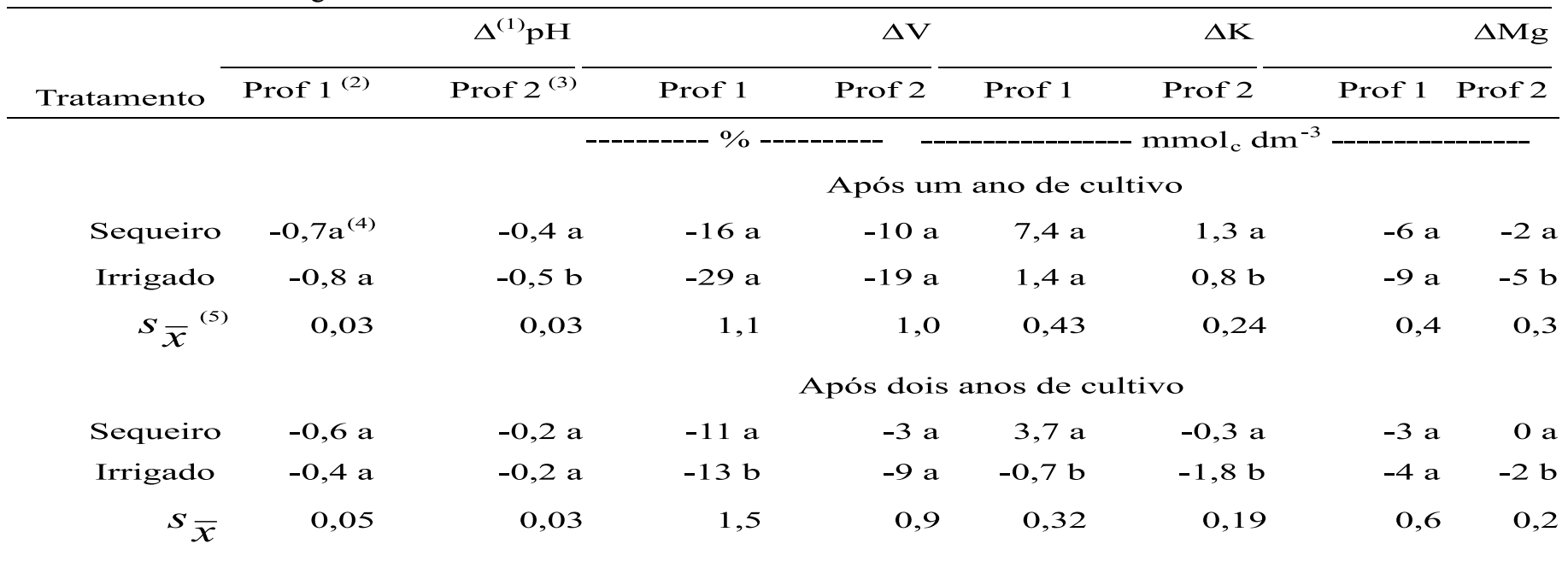

(1) $\Delta$ = valor obtido nas amostragens após o período de cultivo (um ou dois anos) - valor inicial; ${ }^{(2)}$ Prof $1=0$ a $20 \mathrm{~cm} ;{ }^{(3)}$ Prof $2=20$ a $40 \mathrm{~cm}$; ${ }^{(4)}$ valores num mesmo ciclo de cultivo e profundidade seguidos por letras iguais não diferem entre si (teste $\mathrm{F}, p>0,05$ ); ${ }^{5}$ ) $s_{\bar{x}}=$ erro padrão da média.

A

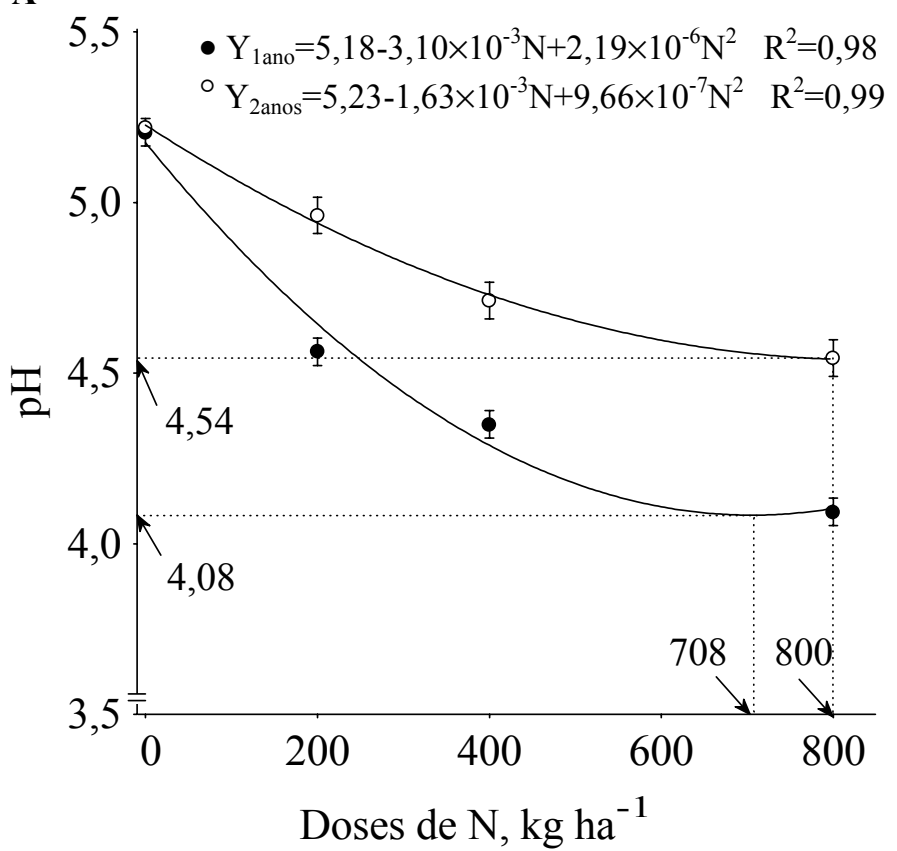

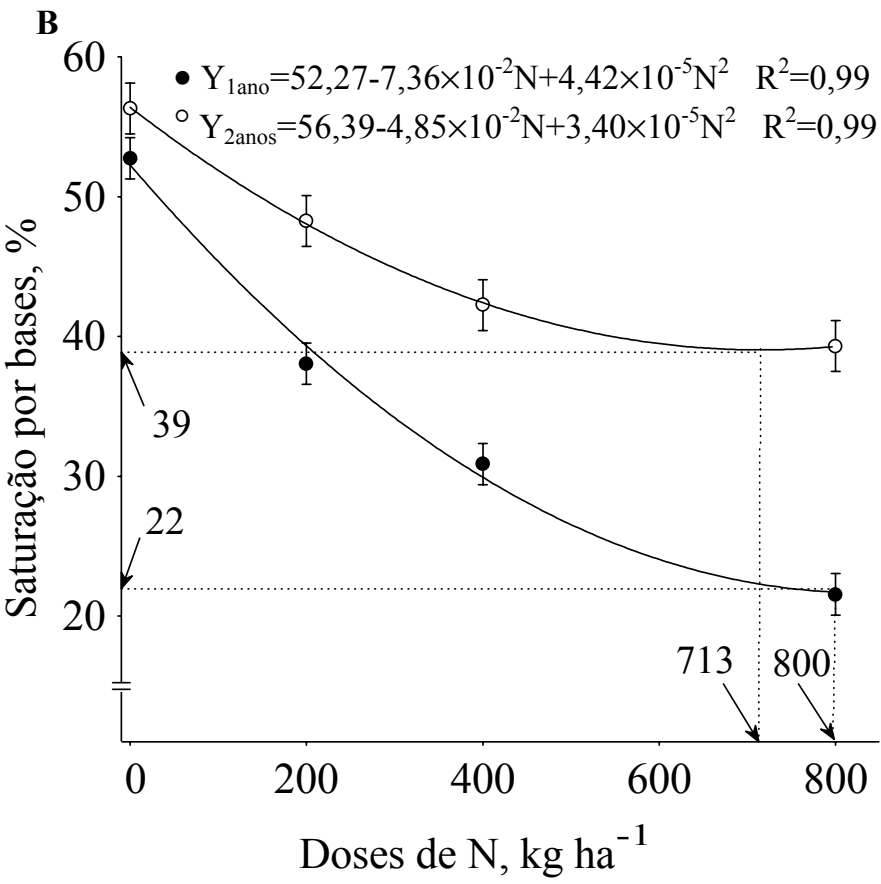

FIGURA 1 - Acidez do solo (A) e saturação por bases (B) $(0$ a 20 cm) em função de doses de $\mathrm{N}$ em bananeira. Barras verticais indicam as médias $(\mathrm{n}=16) \pm$ erro padrão da média.

à dose de $\mathrm{K}$ aplicada. Por meio das regressões, foi possível inferir que a adubação potássica aplicada na superfície teve efeito até a profundidade de $40 \mathrm{a} 60 \mathrm{~cm}$, semelhantemente à tendência descrita por Ritchey (1982) para um Latossolo Vermelho-Escuro.

A variação no $\mathrm{K}$ trocável em função da adubação potássica, em duas condições de irrigação, é apresentada na Figura 4. Em média, para os dois regimes hídricos, cada tonelada de $\mathrm{K}_{2} \mathrm{O}$ aplicada determinou um incremento no $\mathrm{K}$ trocável de $8,5 \mathrm{mmol}_{\mathrm{c}} \mathrm{dm}^{-3}$ na camada de 0 a $20 \mathrm{~cm}$. Observou-se que o efeito da adubação potássica foi maior nas áreas de sequeiro, evidenciado pelos coeficientes angulares das regressões que diferiram $(p<0,10)$ em função do regime hídrico. Credita-se parte desse efeito da irrigação à maior imobilização de $\mathrm{K}$ na biomassa das plantas, o que determinaria que uma fração menor do $\mathrm{K}$ aplicado fosse detectada na análise do solo.

Utilizando-se das regressões apresentadas na Figura 4, estimou-se a dose mínima de $\mathrm{K}_{2} \mathrm{O}$ suficiente para manter o teor de $\mathrm{K}$ trocável da camada de 0 a $20 \mathrm{~cm}$ inalterado em relação à amostragem inicial. Após dois ciclos de cultivo, esses valores atingem $164 \mathrm{e} 618 \mathrm{~kg} \mathrm{ha}^{-1}$ ano $^{-1}$ de $\mathrm{K}_{2} \mathrm{O}$, para sequeiro e irrigado, respectivamente. A preocupação com a sustentabilidade dos cultivos de bananeira, pelo menos em relação à fertilidade dos 


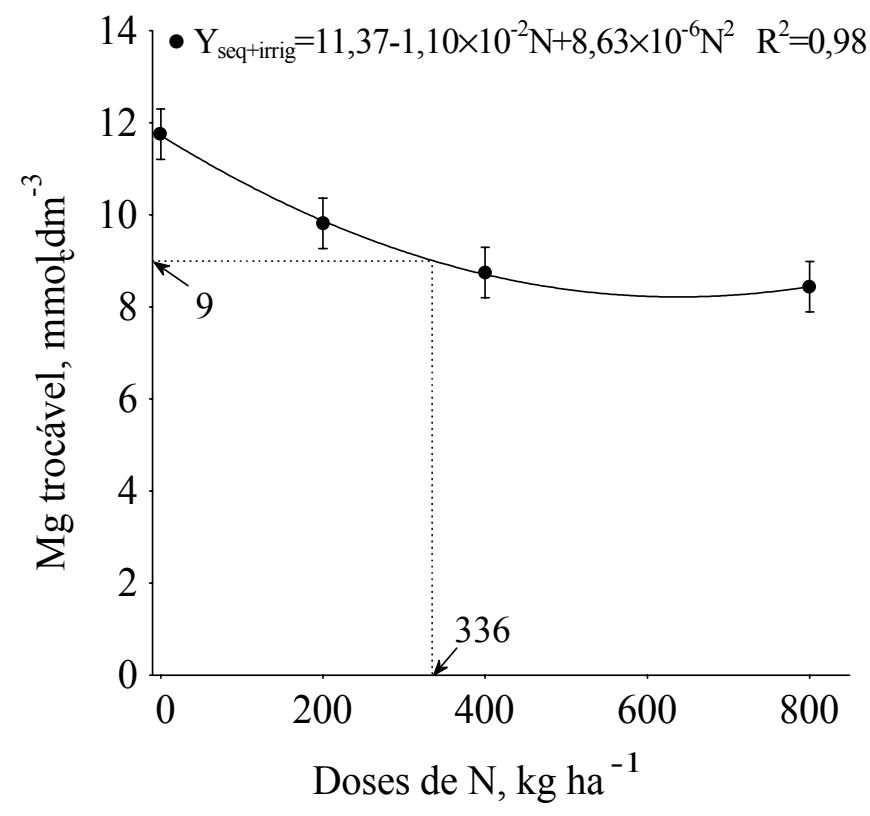

FIGURA 2 - Teor de Mg trocável (0-20 cm) após dois anos de cultivo com bananeira. Valor assinalado corresponde à dose de $\mathrm{N}$ máxima que permitiu manter o teor de $\mathrm{Mg}$ trocável adequado para a cultura $\left(9 \mathrm{mmol}_{\mathrm{c}} \mathrm{dm}^{-3}\right)$. Barras verticais indicam as médias \pm erro padrão da média $(n=16)$.

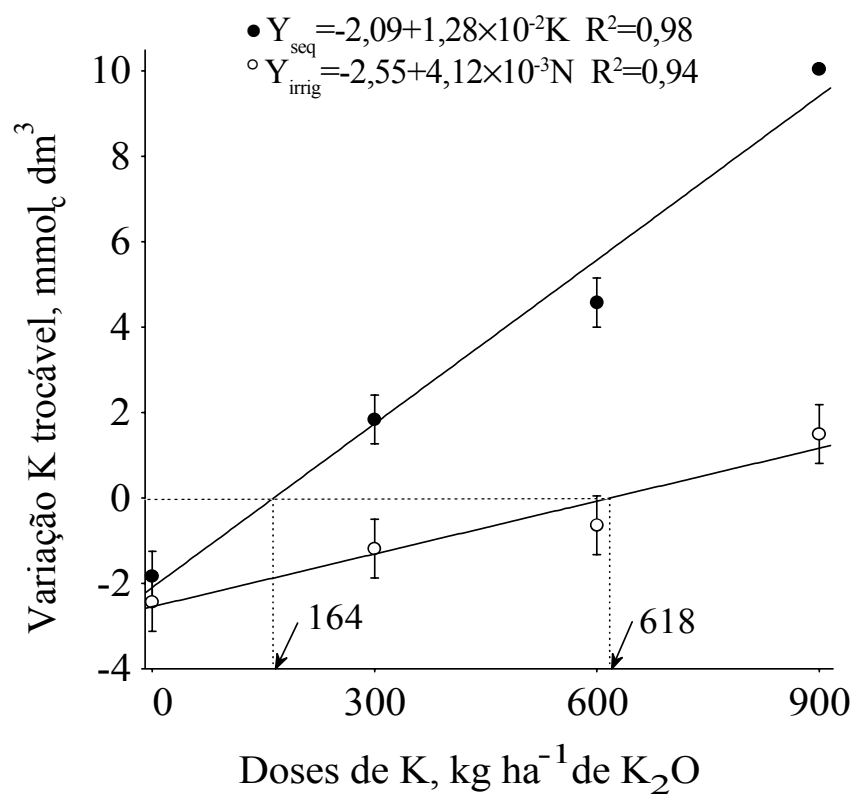

FIGURA 4 - Variação no teor de K trocável (0-20 cm), sob irrigação e sequeiro, após dois anos de cultivo com bananeira. Valores assinalados correspondem à dose de $\mathrm{K}$ mínima para que não ocorresse diminuição no teor de $\mathrm{K}$ troc. Barras verticais indicam as médias \pm erro padrão da média $(n=8)$.
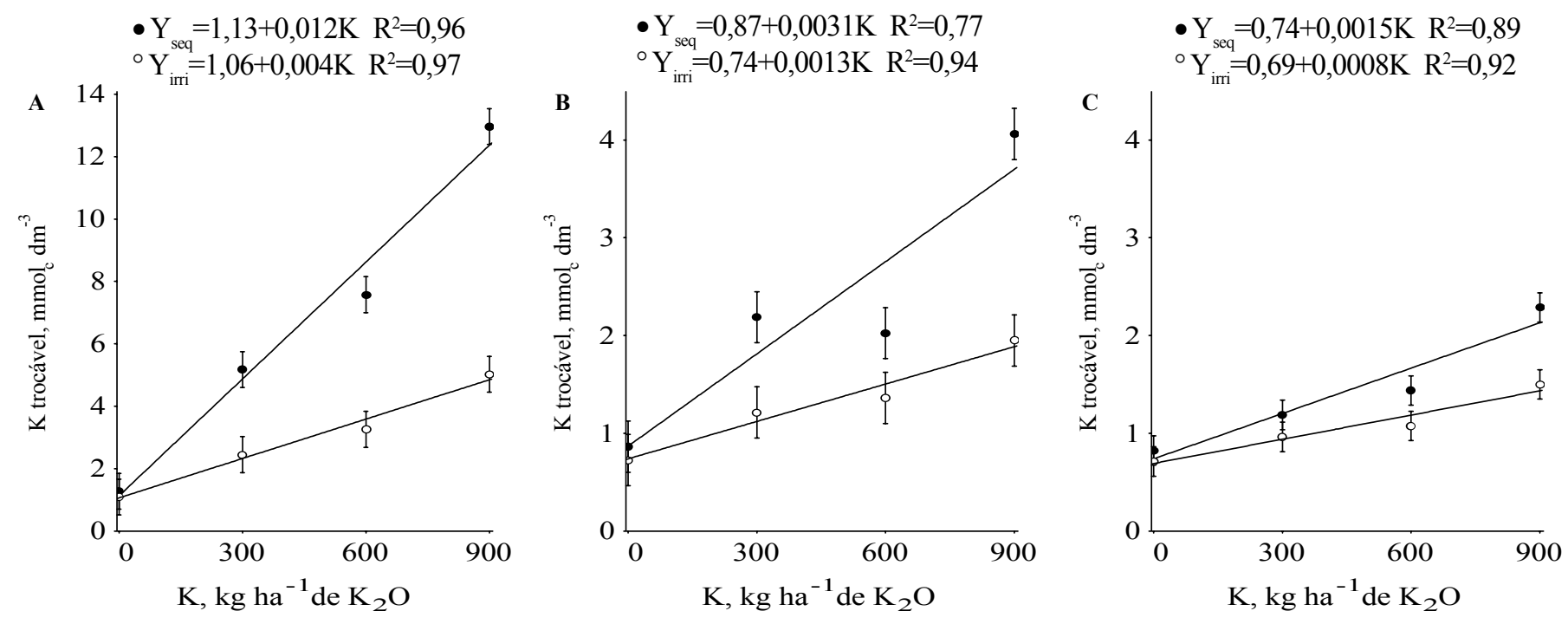

FIGURA 3 - Teor de K trocável em três profundidades de amostragem $(\mathbf{A}=0$ a $20 \mathrm{~cm} ; \mathbf{B}=20$ a $40 \mathrm{~cm}$ e $\mathbf{C}=40$ a $60 \mathrm{~cm})$ após dois anos de cultivo de bananeira. Barras verticais indicam as médias $(n=16) \pm$ erro padrão da média.

solo, é antiga (Jacob \& Uexküll, 1958; Cunha \& Fraga Jr., 1963; Gallo et al., 1972). A grande acumulação de K na biomassa das plantas e a exportação desse nutriente pelos frutos implicam que, mesmo em solos com boas reservas de K, sejam necessárias adubações potássicas em doses elevadas, sem as quais o rendimento da cultura declinará rapidamente (Uexküll, 1985). Saes (1995), num trabalho com 'Nanicão' no Vale do Ribeira (SP), mesmo aplicando potássio regularmente, detectou diminuição no teor de $\mathrm{K}$ trocável de $2,3 \mathrm{mmol}_{\mathrm{c}} \mathrm{dm}^{-3}$ (amostragem inicial) para $0,8 \mathrm{mmol}_{\mathrm{c}} \mathrm{dm}^{-3}$ e $0,6 \mathrm{mmol}_{\mathrm{c}} \mathrm{dm}^{-3}$ no primeiro e segundo anos de cultivo, respectivamente. Esses resultados são indicadores de que a perenidade dos cultivos de bananeira, especialmente sob condições de irrigação, pode ser comprometida em conseqüência do esgotamento acelerado das reservas de nutrientes do solo.

\section{CONCLUSÕES}

1. A adubação nitrogenada em bananeira determinou incrementos significativos na acidez do solo, diminuindo a saturação por bases e teor de Mg trocável. 
2.O cultivo de bananeiras, especialmente sob irrigação, reduziu significativamente o teor de $\mathrm{K}$ trocável do solo em dois ciclos de produção.

3.Os efeitos do cultivo de bananeiras sobre alguns atributos químicos do solo indicam a necessidade de monitoramento periódico da fertilidade, visando à manutenção de condições satisfatórias para a produção, especialmente quanto à acidez $\mathrm{e}$ aos teores de $\mathrm{K}$ e $\mathrm{Mg}$ trocáveis.

\section{AGRADECIMENTOS}

À FAPESP, pelo auxílio financeiro (processo 96/4209-4) e à $\operatorname{Dr}^{\mathrm{a}}$. Aline de Holanda Nunes Maia, pesquisadora da EMBRAPA/Meio Ambiente, pelas orientações para análise estatística.

\section{REFERÊNCIAS BIBLIOGRÁFICAS}

BATAGLIA, O.C., SANTOS, W.R. Efeitos da adubação NPK na fertilidade do solo, nutrição e crescimento da seringueira. Revista Brasileira de Ciência do Solo, Viçosa, v.23, p.881-90, 1999.

CUNHA, J.F., FRAGA JR, C. Efeito da adubação mineral, orgânica e calagem, na produção da bananeira em várzea litorânea de Caraguatatuba - Estado de São Paulo. Bragantia, Campinas, v.22, p.159-68, 1963.

DELVAUX, B. Soils. In: GOWEN, S. (Ed.) Bananas and plantains. London: Chapman \& Hall, 1995. p.230-57.

DOORENBOS, J., KASSAM, A.H. Yield response to water. Rome: FAO, 1979. 193p.

FREUND, R.J., LITTELL, R.C. SAS for linear models: a guide to the ANOVA and GLM procedures. Cary: SAS Institute, 1981. $231 \mathrm{p}$.

GALLO, J.R., BATAGLIA, O.C., FURLANI, P.R., HIROCE, R., FURLANI, A.M.C., RAMOS, M.T.B., MOREIRA, R.S. Composição química inorgânica da bananeira (Musa acuminata Simmonds, cultivar Nanicão). Ciência e Cultura, São Paulo, v.24, p.70-9, 1972.

GODEFROY, J.; DORMOY, M. Dynamique des éléments mineraux fertilisants dans un ferrisol de Martinique sous culture bananière. Application à la programation de la fumure. Fruits, Paris, v.45, n.2,p.93-101, 1990.

GODEFROY, J.; ROOSE, E.J.; MULLER, E. Estimation des pertes par les eaux de ruissellement et de drainage des éléments fertilisants dans un sol de bananeraie de sud de la Côte d'Ivoire. Fruits, Paris, v.30, p. 223-35, 1975.
JACOB, A.; UEXKÜLL, H.von. Fertilizer use: nutrition and manuring of tropical crops. Hannover: Verlagsgesellschaft für Ackerbau, 1958. p.349-65.

LAHAV, E.; TURNER, D.W. Banana nutrition. Berna: IPI, 1983. 62p. (IPI-Bulletin, 7)

LICHTEMBERG, L.A.; MALBURG, J.L. Controle do azul da bananeira pela aplicação de calcário dolomítico. Florianópolis: EMPASC, 1983.7p. (Comunicado Técnico, 67)

LITTELL, R.C.; MILLIKENN, G.A.; STROUP, W.W.; WOLFINGER, R.D. SAS system for mixed models. Cary: SAS Institute, 1996.

LÓPEZ, A.; ESPINOSA, J. Manual de nutricion y fertilizacion del banano. Quito: CORBANA-INPOFOS, 1995. 82p.

MOREIRA, R.S.; HIROCE, R. Diagnose do "Azul-da-bananeira" no litoral Sul Paulista. Bragantia, Campinas, v.37, p.59-63, 1978.

RAIJ, B.van; QUAGGIO, J.A. Métodos de análise química de solo para fins de fertilidade. Campinas: IAC, 1983.31p. (Boletim Técnico, 81)

SAES, L.A. Resposta da bananeira "nanicão" à calagem na região do Vale do Ribeira. 1995. 82f. Dissertação (Mestrado em Agronomia) - Escola Superior de Agricultura Luiz de Queiroz, Universidade de São Paulo, Piracicaba, 1995.

SANCHES, A.C.; SILVA, A.P.; TORMENA, C.A.; RIGOLIN, A.T. Impacto do cultivo de citros em propriedades químicas, densidade do solo e atividade microbiana de um podzólico vermelhoamarelo. Revista Brasileira de Ciência do Solo, Viçosa, v.23, p.91-9, 1999.

SOTO, M. Bananos: cultivo y comercialización. 2.ed. San José: LIL, $1992.674 \mathrm{p}$.

TEIXEIRA, L.A.J.; SPIRONELLO, A.; QUAGGIO, J.A.; FURLANI, P. Banana. In: RAIJ, B. van et al. (Ed.) Recomendações de adubação e calagem para o Estado de São Paulo. 2.ed. Campinas: IAC, 1996. p.131-2. (Boletim Técnico, 100)

TISDALE, S.L., NELSON, W., BEATON, J.D. Soil fertility and fertilizers. 4.ed. New York: Macmillan Publishing Company, 1985. $754 \mathrm{p}$.

UEXKÜLL, H.R. von. Nutrition of plantation crops. In: MUNSON, R.D. (Ed.) Potassium in agriculture. Madison: ASA/CSSA/SSSA, 1985.p.929-59. 